\title{
CAUSAS DE PÉRDIDA DE DIVERSIDAD BIOLÓGICA
}

\section{Octavio Monroy-Vilchis}

CIBIO, Universidad de Alicante

\section{INTRODUCCIÓN}

La diversidad biológica se puede definir como la variedad de formas de vida así como sus interacciones entre si y con el ambiente físico. A la diversidad biológica, con el fin de organizar y facilitar su estudio, se le puede considerar en diferentes niveles como son: a) los paisajes o ecosistemas, b) asociaciones o comunidades, c) especies, d) poblaciones y e) genes. Esta clasificación espacial estriba en que muchas estrategias de conservación están basadas en el contexto geográfico (Soulé 1991), aunque se tiene que considerar que los sistemas biológicos son dinámicos tanto en espacio como en tiempo. En el mundo se han descrito aproximadamente 1.75 millones de especies y se piensa que varios millones más están aún por descubrir.

La diversidad biológica, se distribuye espacialmente de manera diferencial entre los continentes y países, de tal manera que existen regiones con

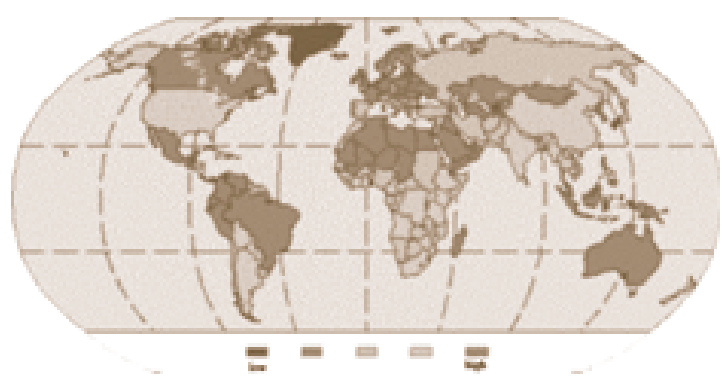

Figura 1. Diversidad biológica a nivel mundial. mayor diversidad biológica, debido principalmente a cuestiones históricas y a factores abióticos (Figura 1) (UNEP-CDB. 2001).

\section{CAUSAS DE PÉRDIDA DE DIVERSIDAD BIOLÓGICA}

La pérdida de diversidad biológica conduce a la extinción de las especies (Wilson 1996). En el tiempo geológico, todas las especies tienen un periodo finito de existencia. La extinción de especies es por lo tanto, un proceso natural que ocurre sin la intervención humana. Sin embargo, las extinciones ocasionadas directamente o indirectamente por los humanos ocurren con un coeficiente que excede cualquier estimación razonable de los antecedentes de la extinción. Según informes de la Unión Mundial para la Conservación de la Naturaleza (UICN), 15.500 especies de animales y vegetales están en peligro de extinción en el mundo y se menciona que una de cada tres especies de anfibios, casi la mitad de las de tortugas de agua fresca, una de cada ocho especies de aves y una de cada cuatro de mamíferos están amenazadas. Aunque las especies consideradas en peligro por la UICN son un $1 \%$ del total de las registradas por los científicos, entre ellas figura un $12 \%$ de las de aves, un $23 \%$ de los de mamíferos y un $32 \%$ de todas las plantas gimnospermas, en su mayoría coníferas y cícadas. Los datos son probablemente más precisos para aves y mamíferos por ser especies más conspicuas (Tabla 1). 


\begin{tabular}{|c|c|c|c|c|c|}
\hline Continente $^{a}$ & Isla $^{b}$ & Océano & Total & $\begin{array}{l}\text { Número } \\
\text { aproximado } \\
\text { de especies. }\end{array}$ & $\begin{array}{l}\text { Porcentaje de } \\
\text { Taxa extintos } \\
\text { desde } 1600\end{array}$ \\
\hline \multicolumn{6}{|l|}{ Mamíferos } \\
\hline 30 & 51 & 2 & 83 & 4,000 & 2.1 \\
\hline \multicolumn{6}{|l|}{ Aves } \\
\hline 21 & 92 & 0 & 113 & 9,000 & 1.3 \\
\hline \multicolumn{6}{|l|}{ Reptiles } \\
\hline 1 & 20 & 0 & 21 & 6,300 & 0.3 \\
\hline \multicolumn{6}{|l|}{ Anfibios } \\
\hline 2 & 0 & 0 & 2 & 4,200 & 0.0 \\
\hline \multicolumn{6}{|l|}{ Peces $^{c}$} \\
\hline 22 & 1 & 0 & 23 & 19,100 & 0.1 \\
\hline \multicolumn{6}{|l|}{ Invertebrados $^{\mathrm{c}}$} \\
\hline 49 & 48 & 1 & 98 & $1,000,000+$ & 0.0 \\
\hline \multicolumn{6}{|l|}{ Plantas vasculares $^{\mathrm{d}}$} \\
\hline 245 & 139 & 0 & 384 & 250,000 & 0.2 \\
\hline \multicolumn{6}{|l|}{ Total } \\
\hline 370 & 351 & 3 & 724 & & \\
\hline $\begin{array}{l}\text { a. Masas terrestres más g } \\
\text { b. Masas terrestres meno } \\
\text { c. Totales principalmente } \\
\text { d. Taxa Vasculares (inclu }\end{array}$ & $\begin{array}{l}\text { des de } 1 \\
\text { a } 1 \text { millc } \\
\text { resentat } \\
\text { especies, }\end{array}$ & $\begin{array}{l}\text { de kilómetr } \\
\text { kilómetros c } \\
\text { le Norte Ame } \\
\text { species y var }\end{array}$ & $\begin{array}{l}\text { rados (el tam } \\
\text { s. } \\
\text { Hawaii. }\end{array}$ & de Groenlandia). & \\
\hline
\end{tabular}

Tabla 1. Extinciones registradas de 1600 a 1983. (Bryant 2002).

\section{CRECIMIENTO POBLACIONAL HUMA- NO Y LA SOBREEXPLOTACIÓN DE RECURSOS NATURALES}

Las amenazas contra la diversidad biológica, son causadas principalmente por el crecimiento poblacional humano. La mayor destrucción de comunidades biológicas ha ocurrido en los últimos 150 años, durante los cuales el crecimiento poblacional humano ha ido de 1 billón en 1850 a 6.2 billones a inicios del 2002, y se proyecta que será de 10 billones para 2050. Se ha argumentado que tales cifras son incompatibles con procesos ecológicos y evolutivos naturales principalmente de grandes depredadores, la migración de las aves, la protección y manutención de ambientes naturales nativos (Soulé 1991). El crecimiento poblacional ha disminuido en países desarrollados y por el contrario ha incrementado en muchas áreas de África, Latinoamérica y Asia, lugares donde se encuentra la mayor diversidad biológica. El crecimiento poblacional humano, es parcialmente responsable de la pérdida de diversidad biológica ya que la sobreexplotación de recursos también la incrementa.

El aumento del capitalismo industrial y las sociedades modernas materialistas han incrementado su demanda de recursos naturales particularmente en países desarrollados. El uso ineficiente y derrochador de los recursos es la principal causa de la pérdida de diversidad biológica (Primack 2002). La gente en los países industrializados (como en Estados Unidos, Francia y Japón) comprende una cuarta parte de la población mundial. Sin embargo, consume tres cuartas partes de los recursos. Cada año, los Estados Unidos con el 5\% de la población mundial, usa aproximadamente el $30 \%$ de los recursos naturales mundiales. El promedio anual de uso de energía de un ciudadano Estadounidense es 17 veces el de un ciudadano chino, y el consumo de productos de papel es 79 veces superior (WRI 2000). 


\section{CONTAMINACIÓN}

Las comunidades biológicas, pueden estar amenazadas por factores externos que no modifican de manera inmediata la estructura de las especies dominantes. La más sutil y universal forma de degradación ambiental es la contaminación, comúnmente causada por pesticidas y otros compuestos químicos, aguas residuales (vertidas por industrias y zonas urbanas), las emisiones de fábricas y de automóviles. Los efectos de la contaminación en la calidad del agua, aire y suelo aumentan la pérdida de diversidad biológica (Primack 2002). Es conocido el efecto de la contaminación por pesticidas (DDT y otros compuestos) sobre las cadenas tróficas y de cómo su concentración se incrementa conforme se asciende en el nivel trófico (biomagnificación). Un ejemplo de esto es lo ocurrido con las poblaciones de aves rapaces debido a que se alimentan de aves que consumen insectos, los cuales, a su vez, son expuestos a los plaguicidas ocasionando en las rapaces huevos con cascarón débil, que se rompían durante la incubación, provocando declinaciones en poblaciones de rapaces. En lagos y estuarios el DDT y otros pesticidas se han concentrado en peces depredadores y mamíferos marinos (Primack 1995).

La contaminación del agua, tiene consecuencias negativas en la biodiversidad de especies acuáticas. Los ríos, lagos y océanos generalmente son usados como drenajes en la gran mayoría de los asentamientos humanos y por la industria. Pesticidas, herbicidas, petróleo, metales pesados, detergentes, materia orgánica son frecuentemente vertidos a los cuerpos de agua ocasionando su eutrofización, y al mismo tiempo disminuyendo la cantidad de agua disponible para el establecimiento y uso de otras especies. Si los organismos no mueren de manera inmediata, estos químicos pueden hacer el ambiente $\tan$ inhabitable que estos disminuyen su tasa de supervivencia. Al contrario que un ecosistema terrestre contaminado, en que los efectos son principalmente locales, los desechos tóxicos en ambientes acuáticos se difunden sobre un área amplia (Primack 2002).

La contaminación de aire ha provocado en el norte de Europa y este de Norteamérica debilita- miento en varias especies de árboles, haciéndolos más susceptibles a ataques por insectos, hongos y enfermedades. Cuando los árboles mueren, otras especies en los bosques se extinguen localmente. La contaminación del aire ocurre principalmente por verter nitratos y sulfatos entre otros a la atmósfera, los que a su vez producen ácido nítrico y ácido sulfúrico ocasionando la lluvia ácida, que ha provocado disminución en poblaciones de anfibios e inhibición en los procesos de descomposición por parte de microorganismos (Primack 1995, 2002).

Una de las causas del cambio climático global se debe a que el bióxido de carbono, metano, otros gases traza y el vapor de agua (nubes) en la atmósfera, permiten pasar los rayos solares a la superficie de la tierra pero disminuyen la tasa de escape de la energía radiada por la tierra (calor) hacia el espacio. Esto se denomina efecto invernadero, y tiene un mayor impacto en sitios que están en altas latitudes en comparación con los de más bajas latitudes (Soulé 1991).

\section{INTRODUCCIÓN DE ESPECIES EXÓTICAS}

Una especie exótica es aquella que ha sido llevada, por el hombre, a un sitio en el que no es nativa y esta acción ha modificado su distribución natural históricamente definida por barreras abióticas y bióticas (capacidad de dispersión, alimento, depredadores entre otros). Estas especies exóticas, pueden convertirse en invasoras y traer graves consecuencias. Generalmente, este movimiento de especies se ha dado para satisfacer las necesidades inmediatas del hombre en los lugares a donde arriba. Las introducciones, de manera general, han ocurrido por las siguientes causas: las colonizaciones de unas naciones a otras, cuando los colonizadores llegaban a sus nuevos destinos lo hacían con animales y plantas de su país de origen, para iniciar su cultivo o crianza en el nuevo sitio bajo condiciones poco controladas; convirtiéndose de esta manera la horticultura, agricultura y ganadería, en actividades que propiciaron la introducción de especies exóticas. El transporte accidental, ha sido también otra causa que ha motivado la introducción de especies exóticas, algunas especies han sido transportadas de manera no intencional por el 
hombre cuando este viaja de un lugar a otro por ejemplo en barcos (algas, roedores, artrópodos, semillas), aeroplanos (artrópodos, semillas, roedores) o en el mismo hombre (parásitos, virus, bacterias) (Primack 1995). También se ha dado la introducción deliberada con el fin de utilizar algunas especies como control biológico. Cuando una especie exótica ocasionaba problemas en un sitio, una solución común era traer un depredador natural e introducirla para controlar a la primera; pero ésta última llegaba a depredar también sobre especies nativas, disminuyendo sus poblaciones (Primack 2002).

Las especies exóticas, pueden desplazar a las especies nativas por competencia limitando los recursos; además pueden ser depredadores de especies nativas o pueden modificar el ambiente natural de tal manera que perjudican a las especies nativas. Las especies exóticas, pueden presentar mayor capacidad que las nativas de invadir y dominar nuevos ambientes naturales debido a la ausencia de sus depredadores naturales, parásitos o enfermedades y a su vez, estas especies, pueden introducir nuevos parásitos o enfermedades a los ambientes naturales provocando mortandad en las especies nativas.

\section{ENFERMEDADES}

Una amenaza más a la diversidad biológica es el incremento en la transmisión de enfermedades como resultado de las actividades humanas como destrucción del hábitat, interacción con humanos. Las infecciones pueden venir de microparásitos como virus, bacterias, hongos o protozoarios o de macroparásitos como helmintos y artrópodos.

\section{EL COMERCIO DE ESPECIES}

Muchas poblaciones de plantas y animales han sido amenazadas debido al comercio de los organismos (mascotas u ornamentales) o de alguna de sus partes (pieles, huesos, esqueletos, garras, flores, etc.). Estos, generalmente son demandados por países industrializados. Los mayores exportadores son los países tropicales y subtropicales mientras que los mayores importadores son Europa, Japón y Estados Unidos (Tabla 2).

\begin{tabular}{|l|l|}
\hline \multicolumn{1}{|c|}{ Exportadores } & \multicolumn{1}{|c|}{ Importadores } \\
\hline Argentina & Canadá \\
Bolivia* & China \\
Brasil* & Comunidad económica Europea \\
África Central & Hong Kong \\
China & Japón \\
Congo & Singapur \\
Guyana & Taiwan \\
Honduras & U.S.A. \\
Indonesia & \\
México* & \\
Paraguay* & \\
Perú & \\
Filipinas & \\
Senegal & \\
Sudáfrica & \\
Korea del sur & \\
Sudan & \\
Taiwan & \\
Tanzania & \\
Tailandia & \\
Turquía & \\
U.S.A. & \\
U.S.S.R. & \\
Zaire & \\
\hline $\begin{array}{l}\text { Fuente: World Wildlife Fund, U.S. Departamento del Interior. } \\
\text { *Países que prohíben las exportaciones de fauna silvestre. El } \\
\text { comercio de especies es ilegal y es enviado a otros países. }\end{array}$ \\
\hline
\end{tabular}

Tabla 2. Se muestra la lista de los mayores paises exportadores e importadores de fauna silvestre (BRYANT 2002).

\section{FRAGMENTACIÓN NATURAL NATIVO}

DEL AMBIENTE

La pérdida o destrucción del ambiente natural nativo llega a ocasionar la fragmentación del mismo, entendiéndose por fragmentación como: el 
proceso a través del cual un gran y continuo hábitat es reducido en área y dividido en dos o más fragmentos (Primack 1995). De esta manera los ambientes naturales nativos, al ser fragmentados por acciones antrópicas como: urbanización, establecimiento de cultivos o potreros, construcción de caminos entre otros; modifican notablemente el paisaje ocasionando discontinuidad en los ambientes naturales así como alteraciones en los procesos ecológicos y en las interacciones de especies nativas modificando su futuro evolutivo en medida que se lleva a cabo la fragmentación. La acción de fragmentación, ocasiona que el paisaje de una apariencia de islas donde los fragmentos están separados entre sí por los diferentes ambientes antrópicos. La dinámica de estos fragmentos puede ser descrita a través del modelo biogeográfico de islas. Los fragmentos difieren del ambiente natural en dos aspectos: los fragmentos presentan una gran cantidad de borde por área de fragmento y el centro de cada fragmento esta más cercano al borde. Esto provoca que los ambientes naturales nativos fragmentados amenacen la existencia de las especies, debido a que la fragmentación puede limitar la dispersión y colonización al no permitir que los organismos lleguen al otro fragmento a través del ambiente destruido o transformado (Primack, 1995). En el caso que el ambiente ya se encuentre fragmentado se recomienda que se generen "corredores" entre los fragmentos, para mantenerlos conectados entre sí y permitiendo el flujo de especies de un fragmento a otro.

\section{PÉRDIDA O DETERIORO DEL AMBIENTE NATURAL NATIVO}

Se conoce que la pérdida o deterioro del ambiente natural nativo es la principal amenaza de disminución de la diversidad biológica resultado de la expansión y actividades de las poblaciones humanas (Primack 2002), siendo su protección el medio más importante para disminuir la pérdida de diversidad biológica. Además, también puede ser la causa principal, de la alteración de procesos ecológicos y la modificación de ciclos biogeoquímicos. Se puede entender la pérdida del ambiente natural nativo de dos maneras: la primera como la pérdida total del ambiente, por ejemplo, cuando se construye una ciudad sobre un área que anteriormente era boscosa. La segunda, como la pérdida parcial (deterioro) del ambiente.

Su impacto depende del tiempo y espacio; ya que existe diferencia de la diversidad de especies entre países tropicales y templados, siendo diferente su vulnerabilidad, ya que en los países tropicales existe una mayor riqueza en menores extensiones de terreno presentando tasas de deforestación más altas.

\section{DEFORESTACIÓN}

En cualquier área boscosa se cortan árboles para construir viviendas, así como para la agricultura y/o ganadería. La madera ha sido la principal fuente de calor, de construcción, de elaboración de papel entre otros. En los últimos 5.000 años, el hombre ha reducido los bosques de aproximadamente el 50\% que ocupaban la superficie del planeta a menos del $20 \%$.

Muchas de las grandes áreas de pastizales en el mundo como las sabanas de África, las del este de Europa y Rusia, las pampas argentinas y algunas de las praderas de Norteamérica fueron bosques antes del disturbio humano. En las zonas secas del mundo como el norte de África, Grecia, Italia y Australia, las zonas deforestadas se sobrepastorearon y perdieron suelo rápidamente y ahora sufren procesos de desertificación. De acuerdo con las estimaciones de Myers (1989, 1992), los bosques han sido destruidos a una tasa de $150.000 \mathrm{~km}^{2}$ por año con diferencias entre continentes. La determinación de las tasas de deforestación ha sido un tema muy controvertido. La Organización de la alimentación y agricultura (FAO), estimó en 1991 una deforestación de $134.000 \mathrm{~km}^{2}$. Mas del 50\% de hábitat naturales han sido destruidos en países tropicales del viejo mundo (WRI 2000). La deforestación esta concentrada en pocos países, de forma que el $50 \%$ de la deforestación global ocurre en 10 países en desarrollo.

Varios de los países donde se han documentado las tasas más altas de deforestación, son también aquellos que presentan mayor diversidad biológica del planeta (Tabla 3). A su vez, la deforestación esta relacionada con la superpoblación y la pobreza de las regiones. 


\begin{tabular}{lccc}
\hline Country & Species richness & Endemism & Total \\
\hline Brazil & 30 & 18 & 48 \\
Indonesia & 18 & 22 & 40 \\
Colombia & 26 & 10 & 36 \\
Australia & 5 & 16 & 21 \\
Mexico & 8 & 7 & 15 \\
Madagascar & 2 & 12 & 14 \\
Peru & 9 & 3 & 12 \\
China & 7 & 2 & 9 \\
Philippines & 0 & 8 & 8 \\
India & 4 & 4 & 8 \\
Ecuador & 5 & 0 & 5 \\
Venezuela & 3 & 0 & 3 \\
\hline
\end{tabular}

"From Mittermeier et al. (1997).

Tabla 3. Se muestra una lista de los paises con mayor diversidad biológica, considerando principalmente la riqueza y endemismos de mamiferos, plantas, peces, mariposas y aves.

A partir de los datos proporcionados por la FAO (2003) y aplicando modelos de regresión lineal se puede deducir lo siguiente: la tasa de crecimiento del bosque se relaciona más con la tasa de crecimiento poblacional $(\mathrm{r} 2=31.06)$, seguida de la tasa de crecimiento económico anual $(\mathrm{r} 2=12.9)$, lo que sugiere que a menor tasa de crecimiento poblacional y mayor tasa de crecimiento económico de los países con mayor diversidad, menor será la pérdida de los bosques. Esto ya se ha comentado por varios autores, lo que se tiene que continuar haciendo es la cuantificación y análisis de otras variables como la tasa de utilización de recursos per capita por país que puedan evidenciar la relación restante (aprox. 50\%) de la tasa de la pérdida del bosque.

\section{CAUSAS DE LA DEFORESTACIÓN}

No hay sólo una causa de deforestación, ya que es el resultado de la interacción de fuerzas sociales, económicas, políticas y culturales con el ambiente (Ghazoul y Evans, 2001).

\section{a) Crecimiento poblacional y pobreza}

El crecimiento poblacional es una de las causas que más se comentan como incremento de la deforestación tropical. La población se incrementa en 1000 millones cada década y mucho de este incremento ocurre en países en desarrollo, en los que la deforestación es mayor. La pobreza rural, tiene muy pocas opciones económicas y son forzados a tomar decisiones a corto plazo. Estas decisiones son la tala de los bosques para establecer cultivos de subsistencia, limitados por la falta de capital rural, la falta de infraestructura y de educación.

\section{b) Politicas de desarrollo e impuestos incentivos}

Los departamentos de pago constituyen una gran proporción del presupuesto de varios países tropicales, y el ajuste de programas estructurados introducen como un resultado favorecer la maximización del intercambio de moneda a través de la deforestación no sostenible del bosque a campos de cultivo para exportar los granos. También, la agricultura extensiva a gran escala, es motivada por la provisión de subsidios estatales, la reducción de rentas y de impuestos de importación.

\section{c) Uso de agroquímicos}

Gran parte de la tierra agrícola de países tropicales es apropiada por propietarios de grandes tierras o corporaciones que aceleran e incrementan la producción a través del uso de pesticidas y fertilizantes químicos a gran escala, provocando una mayor y más acelerada pérdida de diversidad biológica.

\section{d) Demandas del mercado}

Como las poblaciones crecen, la demanda en los productos del bosque incrementa, particularmente la de madera industrial y de material para hacer papel.

\section{e) Subvaloración del bosque y sus productos}

No se ha valorado correctamente los bosques, se tiene que continuar trabajando en estrategias 
de valoración de la diversidad biológica a través de los servicios ambientales que ofrece, así como los productos que se pueden obtener de un bosque.

\section{f) Instituciones gubernamentales débiles}

Casi todos los países tienen políticas y leyes explicitas para conservar los bosques, pero dos cosas incrementan el riesgo a la deforestación. Primero, es la gran extensión de los bosques, estando muchas veces en lugares remotos siendo lugares fáciles para acciones ilegales.

\section{LITERATURA CITADA}

GHAZOUL J. Y J. EVANS. 2001. Deforestation and land clearing. En: Levin S. (Ed. En jefe). 2001. Enciclopedia de biodiversidad. Volumen 2. Academic Press. U.S.A. 23-36.

MEFFE G. Y R. CARROLL. 1997. Principles of conservation biology. Sinauer Associates Inc. Segunda edición, U.S.A., 729 pp.
PRIMACK R. 1995. A primer of conservation biology. Sinauer- Sunderland. U.S.A, 277 pp.

PRIMACK R. 2002. Essentials of conservation biology. Tercera edición. Sinauer Associates. U.S.A., 699 pp.

RESS W. 2001. Ecological footprint. Concept of. En: Levin S (Ed. En jefe). 2001. Enciclopedia de biodiversidad. Academic Press. U.S.A. Vol.(1):229-244.

SARUKHÁN J. Y R. DIRZO. 2001. Biodiversityrich countries. En: Levin S (Ed. En jefe). 2001. Enciclopedia de biodiversidad. Volumen 1. Academic Press. U.S.A. 419-436.

SOULÉ M. 1991. Conservation: Tactics for a constant crisis. Science, 253: 744-750.

UNEP-CDB. 2001. Global biodiversity outlook. Secretaría de Conservación de la Diversidad Biológica. Canadá, 282 pp.

WILSON, E. O. (1986). Biodiversity. Washington: National Academy Press.

WORLD RESOURCES INSTITUTE. (WRI). 2000. World Resources 2000-2001. World Resources Intitute, Washington, D.C. 